\title{
Aproximación a la masonería española en Estados Unidos
}

\author{
Susana Cuartero Escobés \\ Doctora en Historia, Universidad de Zaragoza. Miembro del Centro de Estudios Históricos de la \\ Masonería Española. \\ Correo electrónico: scescobes@gmail.com
}

Fecha de recibido: 15 de marzo de 2015 - Fecha de aceptación: 13 de abril de 2015

\section{Palabras clave}

Estados Unidos, jurisdicción, masonería española, territorialidad, Lausanne, Asociacion Masonica Internacional

\section{Keywords}

United States, jurisdiction, Spanish Freemasonry, territoriality, Lausanne, International Masonic Association

\section{Resumen}

Este artículo analiza la apertura de logias masónicas españolas en los Estados Unidos. Realmente sorprende el hecho de que entre 1890 y 1920, aproximadamente, hubiera más de cuarenta logias españolas, en un territorio en el que ya existía masonería. ¿Por qué se dio este hecho? ¿Quién estaba detrás de las logias españolas? ¿O cuáles eran sus preocupaciones? Son cuestiones que se intentarán de responder en este trabajo, siempre teniendo en cuenta que se utiliza documentación procedente de diferentes logias, en la mayoría de los casos escasa y muy fragmentada.

\begin{abstract}
This article analyses the opening of Spanish Masonic lodges in the United States. It is quite surprising that between approximately 1890 and 1920, the U.S. had more than forty Spanish lodges in a territory where American Freemasonry already existed. Why is this fact given? Who was behind the Spanish lodges? What were their concerns? These are questions that this work will try to answer, keeping in mind that documents are from different lodges, and in most cases scarce and highly fragmented.
\end{abstract}

Allí está el Gran Crisol. El Este y el Oeste, el Norte y el Sur, la palmera y el pino, el polo y el ecuador, la media luna y la Cruz, de la misma manera que el Gran Alquimista las une y las funde con sus llamas purificadoras. The Melting Pot, Israel Zangwill

\section{Introducción}

La masonería americana forma parte inseparable de la historia de Europa. Comenzó a partir de un grupo de colonias inglesas y escocesas protestantes que crecieron se desarrollaron y enriquecieron con la llegada de nuevas oleadas de inmigrantes a la vez que se fue creando una cultura propia y nuevas formas políticas. 
"Un mundo nuevo requiere ciencia política nueva", expresó Tocqueville y así fue. La corta vida de los Estados Unidos ha sido un continuo experimentar un sistema político nuevo, la democracia, tomando como referencia de lo que no se debía hacer a la vieja Europa.

\section{Implantación y desarrollo de la masonería en Estados Unidos}

Antes de entrar de lleno en el análisis de la masonería española en Estados Unidos, es obligado centrar la cuestión. Para ello vamos a distinguir dos momentos muy claros en el desarrollo de la institución: en el primero trataremos sobre los orígenes, la llegada y el rápido desarrollo de la Institución en las colonias, y en el segundo, nos ocuparemos de los primeros contactos entre España y Estados Unidos y del asentamiento de las distintas obediencias españolas a finales del siglo XIX.

\section{La masonería anglo-americana y su papel en el nacimiento de los Estados Unidos}

Aunque parezca extraño, no se conocen muchos datos sobre la introducción de la masonería en Estados Unidos. Tan solo comenzamos a tener alguna prueba fiable a partir de 1730-1733, como veremos más adelante.

Antes de esa fecha sabemos que se habían ido produciendo numerosas migraciones procedentes de Inglaterra, Irlanda y Escocia provocadas por las persecuciones religiosas. En los tres lugares había y se conocía la masonería.

A lo largo del siglo XVIII fueron naciendo los estados que formaron Nueva Inglaterra $^{2}$ : Los primeros pobladores eran, en su mayoría, aventureros sin recursos, peregrinos y proscritos unidos para "fundar entre todos una sola familia política y prestarnos asistencia mutua", Para algunos autores esta pretendida sociedad implica que la masonería no era desconocida entre los colonos. Si acudimos al testimonio aportado por Alphonse Cerza observamos que median setenta y cinco años entre la fundación de Jamestown (Virginia) en 1607 y la evidencia del primer masón conocido en la historia de Estados Unidos, en 1682. Su nombre era John Skene y había emigrado a New Jersey desde Escocia donde había sido iniciado en la logia $\mathrm{n}^{\mathrm{o}} 1$ de Aberden. Pero este hombre era de origen escocés y no podemos considerarlo como masón americano. Quien sí lo era, fue Jonathan Belcher, nacido en Boston e iniciado en una logia

\footnotetext{
${ }^{1}$ Alexis de Tocqueville, La Democracia en América (Madrid: Alianza Ed., Madrid, 1980).

${ }^{2}$ Aplicaremos este término a las Trece Colonias que en 1776 se independizaron de la soberanía inglesa pero debemos matizar que las colonias suelen dividirse en tres zonas territoriales correspondiendo el término Nueva Inglaterra tan sólo a cuatro de ellas. En las Colonias del Norte (Nueva Inglaterra) situamos New Hampshire, Massachusetts, Connecticut y Rhode Island; en las Colonias Centrales: New York, New Jersey, Pennsylvania y Delaware y en las Colonias del Sur: Maryland, Virginia, Carolina del Norte, Carolina del Sur y Georgia.

${ }^{3}$ Lorenzo Frau, Diccionario Enciclopédico de la Masonería (México D.F.: Ed. Valle de México, 1979), vol. IV, 147.
} 
masónica en Londres hacia 1704 y afiliado más tarde a la logia de San Juan de su ciudad natal ${ }^{4}$.

A la vista de estos datos podemos pensar que a comienzos del siglo XVIII ya existía masonería en las colonias angloamericanas sin embargo sería una afirmación arriesgada pues no se trataba de una institución organizada, sino más bien, de individuos procedentes de la metrópoli con un elevado nivel cultural y económico. Esta va a ser una característica de la masonería colonial, su vínculo con el poder a través de políticos y hombres de estado.

La creación de la Gran Logia Unida de Inglaterra y los contactos entre las colonias norteamericanas y otras colonias inglesas como Jamaica, contribuyeron a su crecimiento y expansión ${ }^{5}$. A partir de este momento comienza la polémica sobre qué ciudad, Boston o Philadelphia, debe considerarse como la cuna de la masonería, realidad difícil de discernir, como veremos. En 1730 el duque de Norfolk concedió permiso a Daniel Cox para fundar logias en las colonias americanas. Para autores como Findel $^{6}$ ya en el año 1732 una logia de Philadelphia se reunía en la Tun Tavern y fue unos años más tarde cuando la masonería se estableció en Boston. Sin embargo, Cerza cree que fue Henry Price, un londinense emigrado a Boston, quien en 1733 estableció el primer grupo de masones debidamente constituido. Findel reconoce que Price recibió poderes del vizconde de Montagu, Gran Maestre de Inglaterra, para nombrar diputados y unir a los residentes en América en una o varias logias ${ }^{7}$, pero no descarta la posibilidad de que antes de ello existieran logias en otros lugares.

A estas dos opiniones hemos de añadir la de Hughan, para quien Benjamín Franklin fue iniciado en 1731 (posiblemente en el mes de febrero), lo que probaría que ya existían logias en algún lugar diferente a Boston. Además, este autor, reafirma que el Duque de Norfolk concedió patente a Cox para fundar logias en New York, New Jersey y Pennsylvania. Ante toda esta confusión y a falta de pruebas documentales, tomaremos Boston 1733 como comienzo de la masonería en las colonias americanas.

Organizada la primera Gran Logia en Boston, al año siguiente, en 1734, ese mismo grupo fundó otra en Philadelphia de la que fue elegido Venerable Benjamin Franklin. La masonería americana siguió desarrollándose pero no perdió el tinte colonial que le infundió Inglaterra.

Durante el siglo XVIII las relaciones entre Nueva Inglaterra y la metrópoli fueron paulatinamente, deteriorándose. La crisis se agudizó en 1770 con el reinado de Jorge III y los King's Friends. La férrea política colonial así como las humillantes y restrictivas medidas impuestas no gustaron a unos colonos que tras la Paz de Paris (1773) habían desarrollado una mayor conciencia política y una mayor autonomía

\footnotetext{
${ }^{4}$ Alphonse Cerza, "La Masonería en Estados Unidos", Historia 16 (1977): 87-94.

${ }^{5}$ Frederic W. Seal-Coon, An Historical Account of Jamaican Freemasonry (Kingston: Golding Printing Service, 1976).

${ }^{6}$ J. G. Findel, The History of Freemasonry from its Origin Down to The Present Day (London: Asher \& C., London, 1927).

${ }^{7}$ Este hecho tuvo lugar el 30 de julio de 1733, procediendo a fundar la Gran Logia Provincial de Boston bajo el nombre de Gran Logia de San Juan.
} 
administrativa y económica. Fueron estas condiciones y no las presiones políticas o el hundimiento económico derivado de las leyes sobre comercio y transporte las que, poco tiempo después, condujeron a la independencia. El enfrentamiento entre dos tipos de desarrollo diferentes: centralismo metropolitano versus autonomismo colonial.

Hacia 1770 comienza la fundación de los Comités de Correspondencia y los Hijos de la Libertad, germen del posterior movimiento separatista y de los cuales formaron parte personajes tan carismáticos como Samuel Adams, Thomas Jefferson o Richard Lee. Ese mismo año se suprimieron todas las Townshend Duties excepto la del Té y se puede hablar de un período de relativa calma hasta el día del Boston Tea Party en 1773. De aquí en adelante, los hechos se van a ir encadenando hasta culminar el 4 de julio de 1776 con el Bill of Rights en Virginia.

Muchos historiadores afirman que el Boston Tea Party fue preparado por los masones y atribuyen a la Institución un papel destacado. Autores como Cerza lo desmienten debido a la carencia de pruebas documentales. Lo que sí observamos es que, nuevamente, se confunde la actuación de la Institución con la de algunos de sus integrantes y se asocia a la masonería con el desorden público prerrevolucionario. ¿Qué hay de cierto en todo esto?. Investigaciones realizadas por Cerza demuestran que de 56 firmas que figuran en la Declaración de Independencia, nueve son seguro de masones y otras 23 dudosas; de las 39 que aparecen en la Constitución, trece también corresponden seguro a masones y otras siete son probables; y de los 74 generales que tenía George Washington a sus órdenes, 33 eran "hermanos" y quizá otros 15. La proporción es, realmente, elevada y evidencia un gran desarrollo de la Masonería, sobre todo, si la comparamos con otros países, pero no es suficiente como para elevarlo a la categoría de mito $^{8}$.

Según Tocqueville los inmigrantes de las colonias del Norte, a diferencia de los aventureros que fundaron el resto, era gentes acomodadas que "llevaban consigo admirables principios de orden y de moralidad", que más que buscar su mejora económico-social, "perseguían el triunfo de una idea: la libertad"9. Este hecho se vio favorecido por la mayor soberanía de que gozaron estas colonias en relación con las de otros países. En un contexto de libertades limitadas, la libertad en sí misma se convirtió en la idea predilecta de esa amplia common people que disfrutaba de un bienestar en aumento. La conciencia de todo ese grupo se fue consolidando en torno a la expresión: "Cada ciudadano es rey" y, finalmente, todos los principios quedaron compilados en un solo documento, la Declaración de Independencia redactada por Jefferson.

La ideología recogida en ella tomó cuerpo en suelo americano pero no hemos de olvidar que, en alguna medida, tenía la impronta del Enciclopedismo y de la Ilustración francesa. Uno de los nexos de unión entre Francia y Nueva Inglaterra fue Franklin quien contaba entre sus amigos con Court de Gébelin, Diderot, D’Alembert, Lfayette e incluso el mismo Voltaire.

\footnotetext{
${ }^{8}$ Cerza, "La Masonería en Estados Unidos", 90.

${ }^{9}$ Tocqueville, La democracia en América, 35
} 
Pero no sólo Franklin, Jefferson y Washington, los tres prohombres americanos por excelencia, fueron masones; hubo muchos más partidarios de la independencia que también lo eran. Uno de ellos el 18 de marzo de 1776, declaraba al Pennsylavania Packet: “¿No pertenece acaso la mitad de los bienes de Filadelfia a hombres que llevan mandil? $[\ldots]$ ¿Y no pertenece la otra mitad a hombres cuyos padres o abuelos llevaron mandil?". Esta aseveración nos relaciona a la masonería con otra clase de personas, la clase propietaria puesto que tenían bienes.

Hasta aquí es innegable la implicación de la masonería en la política, en el poder. Sin embargo no se le pueden atribuir a la Institución los hechos que condujeron a la Independencia. Fueron politólogos, militares, propietarios y gente común quienes la llevaron a cabo. Otra cosa es que muchos de ellos pertenecieran a una misma sociedad.

Terminada la guerra se siguió trabajando por la libertad. Ahora se iba a tratar con más ahínco la complicada cuestión de la esclavitud. El empeño de los cuáqueros de Pennsylvania en ello era grande ${ }^{10}$ y en 1790 se dirigieron a Franklin para que elevara una protesta al Congreso sobre el comercio de esclavos. Otra vez encontramos a Franklin encabezando una importante misión, ahora como Presidente de la Sociedad Abolicionista y esta cuestión sí que era complicada pues la esclavitud era más el soporte de una sociedad lejanamente aristocrática, el Sur, que una institución que se pudiera abolir por el simple dictado de una ley. En 1776 las Trece Colonias se unieron contra un enemigo externo que les restringía la libertad; a estas alturas, la Unión comenzaba a resquebrajarse por la misma cuestión: la restricción de la libertad.

Esa guerra de Independencia que separó a las Trece Colonias de su metrópoli excepto en el ámbito cultural, fue la causa de la formación de Grandes Logias Independientes. Se establecieron en cada estado ${ }^{11}$ y controlaron los grados simbólicos. Para los altos grados se establecieron otros dos cuerpos, dos Supremos Consejos, uno con jurisdicción sobre el Norte y otro sobre el Sur.

\section{De los primeros vestigios al asentamiento}

Antes de la implantación oficial de las dos únicas obediencias españolas que se asentaron en estados Unidos, el Gran Oriente Español (GOE) y la Gran Logia Simbólica Española (GLSE), tenemos constancia de esporádicos contactos entre masones españoles y extranjeros a título particular.

Durante el siglo XVIII la presencia de la masonería en España fue ocasional; los únicos datos que se refieren a ella "se refieren a denuncias, en la mayor parte de los

\footnotetext{
${ }^{10}$ El cuaquerismo fue fundado en Inglaterra por George Fox (1624-1691). Se trataba de una secta religiosa entre cuyos fines figuraban la repulsa a la violencia y a la guerra y el decidido apoyo a las causas humanitarias y benéficas. Debido a las persecuciones que sufrieron en Inglaterra muchos emigraron a América, instalándose en unas extensas tierras que la Corona había donado al Almirante Penn en pago de una deuda. Esa colonia creció y en 1682 fundó Philadelphia.

${ }^{11}$ En 1777 se creó la de Massachusetts; en 1778 la de Virginia; en 1783 Maryland, en 1786, Pennsylvania, Georgia y New Jersey; en 1787, New York y las dos Carolinas; en 1789, New Hampshire y Connecticut; en 1791 Rhode Island y en 1794 Vermont. Findel, The History of Freemasonry, 59.
} 
casos, de extranjeros que estaban de paso y que habían sido iniciados fuera de España" ${ }^{\prime 2}$. Uno de estos casos es el de Alejandro French, juzgado como hereje por la Inquisición en 1735:

Al poco tiempo de su llegada a las Islas, posiblemente en los últimos meses de 1736, French inicia su primer viaje -que sepamos- a Boston. Lleva el barco cargado de vinos canarios y la misión de construir por cuenta de sus consignatarios, una corbeta. Sus gestiones en el puerto norteamericano, al margen de la venta de los caldos, debieron ser muy positivas, pues según los datos publicados por el Boston News-Letter, a principios de febrero de 1737 (o finales de enero) nuestro capitán estaba listo para poner rumbo a la isla de Madeira, no sabemos si son la finalidad de comprar vinos portugueses. Si retomamos el hilo de sus declaraciones, tenemos que se inició en cierta logia de Boston por "abril o mayo" del año indicado, con la finalidad de facilitar la venta de su mercancía. En efecto, Alejandro French se incorporó a la Royal Exchange Lodge de aquella ciudad el 11 de mayo (o el 30 de abril). El taller en cuestión se había constituido en 1733 bajo la obediencia de la Gran Logia de Inglaterra pero tomó el nombre de St. John en 1792"13.

El siguiente contacto masónico entre España y Estados Unidos, no fue con la metrópoli sino con sus colonias caribeñas: Cuba, Puerto Rico y Santo Domingo. La lejanía, sin duda, daba pie a una mayor tolerancia y, de hecho, en las tres colonias se difundió la Institución antes que en la Península. Puerto Rico, por ejemplo, se presentó como terreno abonado a la expansión masónica americana desde que los primeros presidentes americanos mostraran sus pretensiones territoriales sobre ella. En la parte española de Santo Domingo, se extendió a raíz de la huida de los colonos franceses con motivo de la revolución negra del Guarico (1791-1795).

Por lo que se refiere a la Península, durante los primeros años del siglo XIX, no consta que hubiera contacto formal con Estados Unidos, lo cual no es de extrañar a juzgar por la historia española: reinados de Fernando VII e Isabel II, persecuciones, edictos, prohibiciones, bulas, etc. Hay que esperar a 1878 para encontrar correspondencia entre la logia tinerfeña Teide $\mathrm{n}^{\mathrm{o}} 53$ y la logia Union de Massachussets $^{14}$. Tan sólo se trata de una carta por la que sabemos que la logia canaria prestó dinero al cónsul americano que había enfermado estando en la isla, y la logia Union, todavía no lo había devuelto.

A partir de la década de 1890 la situación cambiará y la masonería española, como ya apuntamos líneas arriba, se instalará en suelo norteamericano.

\footnotetext{
${ }^{12}$ José Antonio Ferrer Benimeli, La masonería española en el siglo XVIII (Madrid: Siglo XXI, 1996), 353.

${ }^{13}$ Manuel de Paz, Historia de la Francmasonería en Canarias (1739-1936) (Santa Cruz de Tenerife: Ediciones del Excmo. Cabildo Insular de Gran Canaria, 1984), 59.

${ }^{14}$ AHNS, Leg. 315-A.
} 


\section{Gran Oriente Español (GOE)}

El aparente orden reinante en el seno de este oriente presidido por Miguel Morayta, propició un notable incremento de talleres de tal modo que pronto comenzaron a extenderse más allá de los límites españoles. Entre los nuevos territorios se encontraba Estados Unidos. El 7 de agosto de 1893 el Gran Oriente Español concedió patente a la logia Christopher Columbus para que trabajara el Rito Escocés Antiguo y Aceptado en Philadelphia. A partir de este momento se sucedieron las solicitudes de constitución de nuevas logias y se desencadenó el conflicto sobre la soberanía del territorio americano en el ámbito masónico.

Las logias adscritas a la obediencia española en el período comprendido entre 1893 y 1900 fueron:

$\begin{array}{ll}\text { Christopher Columbus } \mathrm{n}^{\mathrm{o}} \text { 188 } & \text { Philadelphia (PA) } \\ \text { Pilgrim } \mathrm{n}^{\mathrm{o}} 189 & \text { Allentown (PA) } \\ \text { Abraham Lincoln } \mathrm{n}^{\mathrm{o}} 210 & \text { Philadelphia (PA) } \\ \text { San Juan } \mathrm{n}^{\mathrm{o}} 213 & \text { Weissport (PA) } \\ \text { Delta } \mathrm{n}^{\mathrm{o}} 222 & \text { Chicago (IL) } \\ \text { Lessing } \mathrm{n}^{\mathrm{o}} 232 & \text { Chicago (IL) } \\ \text { Equality } \mathrm{n}^{\mathrm{o}} 237 & \text { East Mauch Chuck (PA) } \\ \text { Agora } \mathrm{n}^{\mathrm{o}} 240 & \text { South Bethlehem (PA) } \\ \text { George Washington } \mathrm{n} 244 & \text { Hazletown (PA) } \\ \text { Jerusalem } \mathrm{n}^{\mathrm{o}} 247 & \text { Philadelphia (PA) }\end{array}$

La logia Christopher Columbus $n^{\circ} 188$, fue sin duda la más importante de cuantas se fundaron; fue la primera y debe ser considerada como la logia madre. Durante los primeros años funcionó como Gran Logia Regional siendo Harry Goode el delegado del Gran Oriente Español. La doble condición de este taller hace que sus actividades sean difíciles de delimitar.

Comenzó a funcionar el 12 de octubre de 1892, coincidiendo con el cuarto centenario del Descubrimiento de América, de modo independiente, sin estar adscrita a la jurisdicción de ningún organismo superior, y fue regularizada por el GOE en agosto de 1893, como ya dijimos anteriormente. Desde ese momento y a pesar de los obstáculos, trabajó sin descanso para extender la masonería del Oriente Español. Hasta tal punto fue así que para 1895 el Oriente Español contaba ya con cuatro logias más, tres en Pennsylvania: Pilgrim, Delta y San Juan, y una en Chicago, Delta, talleres que el 24 de junio de 1896 decidieron reunirse para elegir a quienes integrarían el cuerpo de oficiales de la Gran Logia Regional de los Estados Unidos, con sede en Philadelphia ${ }^{15}$. Los intercambios de información se reducían, casi exclusivamente, a cuestiones

\footnotetext{
${ }^{15}$ Como curiosidad cabe reseñar que hemos de esperar hasta 1898 para encontrar correspondencia escrita con el distintivo de la Gran Logia Regional; hasta entonces se utilizaba el papel timbrado de la logia Christopher Columbus.
} 
burocráticas y de organización: expedición de patentes, compra de títulos y rituales, requisitos para constituir un capítulo Rosa Cruz, etcétera.

Sólo de vez en cuando y siempre de modo entrecortado, pues la documentación conservada está muy fragmentada, hayamos cuestiones de mayor contenido, como el momento en el que Harry Goode en respuesta a una pregunta realizada por José Vic, habla de la "masonería de color" o masonería para negros. Goode dice que "según la Historia de la Francmasonería de Gould (inglés) la primera logia de color se constituyó en 1775 en Boston, Mass. EUA y fue admitida en la Gran Logia de Inglaterra el 28 de septiembre de $1784^{\prime \prime}$. Esta logia tuvo un fin político muy claro, ayudar a los ingleses durante la Guerra de Independencia, de ahí que fueran regularizados por Inglaterra. Sin embargo los americanos también aprovecharon la baza de los hombres de color pues les concedían la libertad a cambio de que lucharan contra los ingleses.

Lo cierto es que a estas alturas de siglo, trabajaban en logias separadas y no eran reconocidos por otras Grandes Obediencias. Allec Mellor es más duro en su opinión: "En el interior de la Masonería americana el problema se ha resuelto de la manera más intransigente, con la segregación radical" ". El Boletín Oficial del Gran Oriente Español, publicaba en el n 250 de febrero de 1913: "El Gran Maestre de la Gran Logia de Pennsilvania ha declarado que un negro, aunque sea bien proporcionado, inteligente y honrado, no puede ser iniciado en la Francmasonería". Tres meses después, una de las. cuestiones que se plantean para debatir en el Congreso Masónico Internacional es precisamente la situación de la raza negra en la masonería.

Otra temática de gran importancia en este tiempo era la colonial. En 1896 Benjamin Butz, Venerable de la logia Pilgrim n ${ }^{\mathrm{o}} 189^{18}$ escribe a Morayta mostrando su preocupación por la cuestión cubana, no tanto por las consecuencias políticas como por el futuro de las relaciones masónicas. Cuba contaba desde más o menos mediados de siglo con un importante grupo de masones de afiliación norteamericana que pronto se convirtió en hegemónico. Esta situación, como expresa el profesor Sánchez Ferré era anómala y peligrosa porque de los problemas masónicos se pasaba fácilmente a los políticos. Así ocurrió. Tras el Congreso Masónico Internacional de 1875 celebrado en Lausanne, Cuba consiguió la independencia masónica y que las obediencias españolas no fueran bien vistas. Conseguida la primera parte, la segunda era cuestión de tiempo ya que los cimientos metropolitanos eran, cada vez, más débiles y los independentistas contaban con el apoyo de un gran número de filibusteros que desde Estados Unidos y desde las islas caribeñas como la propia Jamaica, les servían armas ${ }^{19}$.

Durante 1897 las relaciones entre Philadelphia y Madrid quedaron interrumpidas, no olvidemos que la masonería fue acusada de promover la revuelta tagala de 1896 en Filipinas, los dirigentes del GOE y de la Asociación Hispano-Filipina

\footnotetext{
${ }^{16}$ AHNS, Leg. 265-A.

${ }^{17}$ Mellor, La Masonería, 108.

${ }^{18}$ No sabemos con certeza cuándo se constituyó. Fue en 1893 pero no se especifica el día. Lo que sí es seguro es que el 15 de noviembre de 1893 contaba con dieciséis integrantes.

${ }^{19}$ Seal-Coon, An Historical Account of Jamaican Freemasonry.
} 
fueron detenidos y la institución masónica desapareció. En septiembre de 1898 se restableció la comunicación pero no hubo mayor mención a la pérdida de las colonias españolas que un "sentimos la guerra entre España y Estados Unidos".

Al año siguiente, 1899, Harry Goode no resultó reelegido Gran Maestre pero siguió manteniendo correspondencia personal con Adolfo de Maglia de ahí que sepamos que la logia Euqlity no había pagado la tasa federal ningún año, que las dos logias de Chicago, Delta y Lessing, estaban durmientes en noviembre de 1899 y que otros cuatro talleres se habían separado definitivamente del GOE en favor de la Gran Logia Regional de Pennsylvania (Rito de York): Equality, George Washington, San Juan y Agora.

De la mayoría de las logias abiertas en estos últimos años del siglo XIX tan sólo alcanzamos a saber el título y la localización geográfica. No se conservan apenas datos directos y los que hay son muy dispares; de unas sabemos los nombres de sus integrantes, de otras las profesiones o la edad, pero de ninguna está la información completa. Lo mismo ocurre con los trabajos que realizaban, con las relaciones que tenían entre ellas y con los enfrentamientos entre "escoceses y yorkinos". Al igual que en la Península adoleció de personalismos y protagonismos que perjudicaron el desarrollo de la obediencia.

\section{Gran Logia Simbólica Española (GLSE)}

Sin duda es la obediencia española de la que menos fuentes directas se han conservado $^{20}$. El 10 de julio de 1892 el Boletín de Procedimientos informa de que habían levantado columnas en Estados Unidos estableciendo cinco logias el 4 de julio de 1892. Esa cifra fue incrementándose de modo que en diciembre de 1893 había aumentado a un total de dieciocho:

$\begin{array}{ll}\text { Cosmos } \mathrm{n}^{\circ} 99 & \text { New York (NY) } \\ \text { Acacia } \mathrm{n}^{\mathrm{o}} 100 & \text { New York (NY) } \\ \text { Pilgrim } \mathrm{n}^{\mathrm{o}} 101 & \text { Allentown (PA) } \\ \text { Progress } \mathrm{n}^{\mathrm{o}} 102 & \text { Philadelphia (PA) } \\ \text { Americus } \mathrm{n}^{\mathrm{o}} 103 & \text { Philadelphia (PA) } \\ \text { Chistopher Columbus } \mathrm{n}^{\mathrm{o}} 109 & \text { Philadelphia (PA) } \\ \text { Socrates } \mathrm{n}^{\mathrm{o}} 110 & \text { Brooklyn (NY) } \\ \text { Memphis } \mathrm{n}^{\mathrm{o}} 111 & \text { Chicago (IL) } \\ \text { Liberty } \mathrm{n}^{\mathrm{o}} 112 & \text { Boston (MA) } \\ \text { Atlantique } \mathrm{n}^{\mathrm{o}} 114 & \text { Newwark (NJ) } \\ \text { Isis } \mathrm{n}^{\mathrm{o}} 119 & \text { Chicago (IL) } \\ \text { Hiram } \mathrm{n}^{\mathrm{o}} 120 & \text { Chicago (IL) } \\ \text { Delta } \mathrm{n}^{\mathrm{o}} 121 & \text { Chicago (IL) }\end{array}$

\footnotetext{
${ }^{20}$ La obediencia resultó de la unión de los ritos de Memphis y Mizraim operada por Garibaldi en 1881 aunque la sección española no se fundó hasta el 15 de febrero de 1887 y no fue reconocida por Italia hasta 1889. BP, Año I, nº Programa, 5-X-1889.
} 


$\begin{array}{ll}\text { Osiris }^{\circ} 122 & \text { Chicago (IL) } \\ \text { Danubio } \mathrm{n}^{\mathrm{o}} 133 & \text { New York (NY) } \\ \text { Ernesto Renan } \mathrm{n}^{\circ} 134 & \text { New York (NY) } \\ \text { Giuseppe Mazzini } \mathrm{n}^{\circ} 140 & \text { Chicago (IL) } \\ \text { Pithagoras } \mathrm{n}^{\circ} 146 & \text { Boston (MA) }\end{array}$

Las únicas noticias que tenemos de todos estos talleres proceden del Boletín de Procedimientos, su órgano oficial. Gracias a él sabemos que tuvieron peor fortuna que las logias del GOE: la Progress $n^{\circ} 102$ en 1893 había abatido columnas y sus miembros se habían integrado en logias del GOE; lo mismo ocurrió con la Delta y quizá con la Pilgrim. 1892 fue un año muy activo para las logias de este rito. En el mes de octubre conmemoraron el IV Centenario del Descubrimiento de América quedando plasmado en el Boletín en forma de extensos artículos sobre los hechos. Al igual que el GOE se mostraron reticentes en sus relaciones masónicas con la Gran Logia de la Isla de Cuba por sus tendencias separatistas de tal modo que en el mes de mayo rompieron relaciones.

Tras este esbozo sobre la implantación de la masonería española podemos concluir que fue a asentarse principalmente en el estado de Pennsylvania, en Philadelphia y otras ciudades de su entorno, y en la ciudad de Chicago. Philadelphia a estas alturas había perdido importancia en favor de Nueva York y en Chicago se concentraba gran parte de la industria pesada. Por aquel entonces, las manufacturas ya superaban a los productos agrícolas, encontrándose en pleno auge la actividad industrial. Uno de los motores que favoreció este desarrollo fue la importante inmigración que se produjo en la década de los 1880. Los obreros-trabajadores se convirtieron en consumidores; se incrementó la movilidad social, se desarrollaron las comunicaciones gracias a las potentes inversiones de banqueros y sociedades anónimas y se estabilizó la frontier que se había ido desplazando hacia el oeste. Pero las condiciones laborales distaban mucho de las ideas democráticas americanas según las cuales todo ciudadano debía tener las mismas posibilidades de progreso y enseguida afloraron diferentes tipos de asociacionismo. No era complicado crear un clima fraterno: John Mitchel, presidente de la Unión Minera, decía que el sindicato simbolizaba esa fraternidad. Samuel Gompers, líder del American Federation Labor (AFL) consideraba que el sindicato condensaba en sí mismo las posibilidades de regeneración de la clase obrera, inspiraba unidad, justicia, camaradería, lealtad..., discurso radicalmente diferente al que se daba en Europa y, desde luego, en España.

Hubo una organización a caballo entre ambas, los Knight's of Labor ${ }^{21}$ en la que tuvieron cabida todos los trabajadores, incluyendo negros y mujeres, excepto vendedores de licores, banqueros, abogados y médicos. Las asociaciones norteamericanas tanto en la versión utópica de los Knights como en la más pragmática

\footnotetext{
${ }^{21}$ La asociación creada por los trabajadores textiles de Philadelphia en 1869 , no fue legal hasta 1881. Comenzó siendo una asociación clandestina lo que le valió la condena de la Iglesia católica pero, en 1881, Powderly consiguió su aprobación por el Vaticano.
} 
de la AFL trataron de agrupar a los trabajadores manufactureros, pequeños tenderos, empleados de comercio, etc. Mád que a las tradicionales "profesiones liberales".

Entre el listado de profesiones que hemos podido recuperar en las fuentes consultadas, hay un claro predominio de comerciantes. Tocqueville pensaba que:

El comercio es naturalmente contrario a toda pasión violenta. Es partidario de la moderación, le gustan los compromisos y huye cuidadosamente de la violencia. Es paciente, acomodativo, indirecto y sólo recurre a medios externos si la necesidad le obliga. El comercio hace independientes a los hombres, les da una alta idea de su valor individual, les inculca el deseo de dirigir sus propios negocios y les enseña a triunfar en ellos; los prepara para la libertad, pero los aleja de las revoluciones ${ }^{22}$.

Según esto estaríamos ante una masonería cuyo componente social sería eminentemente conservador o, al menos, no dado al populismo revolucionario de la década de 1890. De hecho no tenemos constancia de que manifestaran preocupación alguna por actos como la huelga de 1891 del American Railway Union, la de 1892 en las instalaciones de la factoría Carneggie, la huelga general en Nueva Orleans, la de los mineros de Tenesse o la de 1894 en la Pullman Palace Car Company a las afueras de Chicago. Ni la masonería española más progresista, la de la Gran Logia Simbólica Española, admitía este tipo de métodos violentos. Todos los orientes españoles abogaban por la instrucción y el diálogo, por ese republicanismo progresista en el que militaba Miguel Morayta, bastante próximo, a la clase media burguesa americana, a los grandes intereses privados y a la aristocracia del dinero.

¿Y qué hay del conflicto colonial?, cabe preguntarse. Esta cuestión nos sirve como nexo de unión entre los dos siglos a través de la figura del presidente William McKinley. Tras la Guerra de Secesión (1861-1865) se llevaron hasta las últimas consecuencias los principios de la doctrina Monroe, en lo que a relaciones exteriores respecta, y la guerra contra España debe ser considerada como la última acción de ella. Ya en 1895 el Secretario de Estado durante la segunda administración de Cleveland, Richard Olney, expresaba en una nota enviada al gobierno británico con motivo de su contencioso con Venezuela:

Los Estados Unidos son prácticamente soberanos en este continente. Su soberanía se extiende a todos los asuntos en los que pueda mediar o intervenir pues las tres mil millas del océano hacen innatural y sin objetivo toda unión duradera entre un Estado europeo y otro americano.

Fue sobre esta interpretación exagerada y ampliada de la Doctrina Monroe sobre la que comenzó a tomar cuerpo la crisis colonial española.

En las elecciones de 1896 venció el candidato republicano William McKinley pero el entorno que le rodeó no fue el más propicio para su mandato. Roosevelt se

\footnotetext{
${ }^{22}$ Tocqueville, La Democracia en América, 216.
} 
convirtió en cabecilla del grupo imperialista que propugnaba el abandono de la política meramente continental. Junto a él importantes estrategas navales como Alfred Mahan quien argumentaba motivos de defensa para justificar su actitud, el pastor protestante Josiah Strong o el senador Henry Cabot Lodge.

El comercio y los grandes negocios no se mostraban proclives a la guerra porque podía provocar el desajuste del comercio transoceánico. Por lo que a las clases trabajadoras respecta, se hacía necesario canalizar toda su protesta hacia un objetivo común: la expansión exterior.

En este contexto, la masonería americana se mostraba partidaria de la independencia, en realidad, ya lo había manifestado desde que consiguió asentarse en Cuba pues las logias bajo jurisdicción estadounidense daban cobijo a rebeldes cubanos a los que instigaban a la sublevación.

Por su parte la política colonial de la masonería española era de no independencia. Sólo querían el asimilismo con España, la obtención de los mismos derechos. El comportamiento de la Institución es bien diferente en los dos países. En Estados Unidos se vio favorecida y salió reforzada; en España tuvo que suspender sus trabajos. Los masones americanos del Gran Oriente Español optaron por una postura ambigua: declaraban estar al lado de España y no querer el enfrentamiento armado entre ambos países pero sus acciones se limitaron a un mero intercambio de correspondencia sin ánimo de crear y mostrar opinión. Proclamarse antibelicistas como hizo el presidente Mckinley, a su vez masón, sólo les hubiera ocasionado más problemas de los que ya tenían.

\section{El siglo XX}

Durante el siglo XX el GOE se consolida llegando a tener más de cuarenta logias bajo su jurisdicción. Extendió su radio de acción a otros estados: Massachusetts, Rhode Island, California y New York sin abandonar Pennsylvania, lo que supuso que las críticas, ataques y acusaciones de la masonería norteamericana por la intromisión en su espacio, se recrudecieran.

De todas las logias existentes en el siglo XIX, tan sólo cuatro superaron la crisis finisecular: Christopher Columbus, Abraham Lincoln, Pilgrim y Jerusalem pero las noticias que tenemos sobre ellas no van más allá de saber los representantes elegidos para la Asamblea General. Lo que sí sabemos es que en 1913 las cuatro estaban en sueños.

Las logias de nueva creación en este siglo XX fueron:

\author{
Jupiter $n^{\circ} 249$ \\ Hiram n ${ }^{\circ} 250$ \\ Mount Lebanon $n^{\circ} 251$ \\ Acacia $n^{\circ} 252$ \\ Nazareth $n^{\circ} 255$
}

Philadelphia (PA)

Frankford (PA)

Philadelphia (PA)

Philadelphia (PA)

Nazareth 


\begin{tabular}{|c|c|}
\hline Mount Carmel $\mathrm{n}^{\mathrm{o}} 256$ & Philadelphia (PA) \\
\hline William McKinley n $^{\circ} 264$ & Philadelphia (PA) \\
\hline Fraternity $\mathrm{n}^{\circ} 265^{*}$ & Philadelphia (PA) \\
\hline Washington $\mathrm{n}^{\circ} 268^{*}$ & Philadelphia (PA) \\
\hline Liberty $n^{\circ} 286^{*}$ & Philadelphia (PA) \\
\hline Lafayette $\mathrm{n}^{\circ} 279^{*}$ & Germantown (PA) \\
\hline Eureka nº293* & Sharon (PA) \\
\hline Delta n 294 & Chester (PA) \\
\hline Normal n $295^{*}$ & California (PA) \\
\hline Fort Burd n $296^{*}$ & Brownsville (PA) \\
\hline Keystone n⿳0297 & Pottsville (PA) \\
\hline Cedar n²98* & Pittsburg (PA) \\
\hline Mount Ophir n²99* & Roscoe (PA) \\
\hline Valley $\mathrm{n}^{\circ} 300^{*}$ & Monongahela (PA) \\
\hline Equality no $301^{*}$ & New Castle (PA) \\
\hline Harry Goode n⿳ $307^{*}$ & Du Bois (PA) \\
\hline Goirdano Bruno no 308 & Philadelphia (PA) \\
\hline Star of the Future $n^{\circ} 317$ & Providence (RI) \\
\hline Benjamin Franklin n ${ }^{\circ} 318$ & Everett (MA) \\
\hline Honor y Justicia n 319 & Boston (MA) \\
\hline Oakmont $\mathrm{n}^{\mathrm{o}} 325^{*}$ & Verona (PA) \\
\hline Capital City no $330^{*}$ & Harrisburg (PA) \\
\hline L’Humanita no 335 & San Francisco $(\mathrm{CA})$ \\
\hline Samaritan no 339 & San Francisco $(\mathrm{CA})$ \\
\hline Orient $n^{\circ} 373$ & Jonstown (PA \\
\hline Star of the East $n^{\circ} 374^{*}$ & Homer City (PA) \\
\hline Susqueana $\mathrm{n}^{\circ} 391^{*}$ & Sellins Grove (PA) \\
\hline Temple of Thruth $n^{\circ} 392$ & Lehighton (PA) \\
\hline Nino Bixio no 397 & New York \\
\hline Mount Olive $\mathrm{n}^{\circ} 402^{*}$ & Shamokin (PA) \\
\hline Universal no 406 & Oakland (CA) \\
\hline Mount Tabor $n^{\circ} 411^{*}$ & Sanbury (PA) \\
\hline Benjamin Franklin $n^{\circ} 414^{*}$ & Brooklyn (NY) \\
\hline Galileo Galiei n ${ }^{\circ} 418^{*}$ & New York \\
\hline Haladas $n^{\circ} 420$ & New York \\
\hline Progressive $n^{\circ} 425^{*}$ & Shenandoha (PA) \\
\hline Ernet Natahn n ${ }^{\circ} 426$ & Brooklyn (NY) \\
\hline
\end{tabular}

De todas las logias marcadas con * tan sólo se conservan listados de miembros, en ocasiones, sin ningún tipo de sello o rúbrica que valide su contenido, y sin ninguna otra fuente como cuadros lógicos o matrices de diplomas con los que poder contrastar la información por lo que su contenido debe ser tomado con cierta cautela. 
Además de todas las logias citadas, hubo tres capítulos: Washington $\mathrm{n}^{\circ} 48$, constituido en 1896 en Allentown superó la crisis finisecular y pervivió durante el sigloXX; Evergreen n ${ }^{\circ}$ 50, creado en 1909 en Philadelphia y Acacia $n^{\circ} 52$ con patente desde 1903 y situado en Philadelphia. En 1909 se aprobó la apertura de otro más titulado Jorge Girod en honor al desaparecido Comendador y localizado en Pittsburg, pero no sabemos si llegó a abrirse.

Es de destacar que la masonería californiana fue más parecida a la española. El componente latino, mayoritariamente italiano, llegó a Estados Unidos en la segunda de las grandes oleadas migratorias, la de 1905-1910. Aunque en pequeña proporción se dejaron sentir de manera beneficiosa en las logias. Muchos masones, por ejemplo, adoptaron nombre simbólico, como en España.

El contexto en el que vivió la masonería española durante esta nueva etapa no fue muy diferente al del siglo XIX. Proliferaron las logias, como en España, pero su fin fue otro. En Estados Unidos la masonería y sociedades similares se convirtieron en centros de evasión: se vestían como potentados, se identificaban mediante signos y pronunciaban discursos.

El asesinato de Mckinley dio comienzo a una nueva era política encabezada por Roosevelt, más enérgico y agresivo Los primeros años del siglo XX no fueron socialmente tranquilos pero las logias seguían sin mostrar su opinión sobre cuestiones profanas. El estallido de la Primera Guerra Mundial sí que provocó inmediatas reacciones en pro de la paz por parte del GOE pero, en Estados Unidos no hubo mención a ello. A partir de 1914 los talleres americanos se vieron inmersos en una crisis que condujo al cierre de muchos de ellos. La Memoria de la Gran Secretaría General de 1916 así lo expresa:

Si nos remontamos más al Norte, a los Estados Unidos nos encontramos ante una incógnita tan llena de escollos que esta Gr.. Secretaría declara encontrarse incapacitada, por ahora, para emitir juicios definitivos y reclama de la Asamblea resoluciones imperiosas para resolver el conjunto de los problemas de esta importantísima y vital ramificación del Gr. $\because$ Or. $\because$ Español, ya sea nombrado un Comité especial de gestión norteamericana, entre los elementos de los dos grandes consejos o dando instrucciones precisas a los mismos para que de una manera efectiva los talleres norteamericanos se incorporen a la vida activa del Gr. $\cdot$ Or. $\cdot$ pudiendo así servirnos en nuestras fuerzas para la resolución de todos nuestros ideales ${ }^{23}$.

Las comunicaciones quedaron profundamente deterioradas debido a la guerra y durante cuatro años apenas hubo contactos. Los sentimientos de Fraternidad Universal no fueron elemento de cohesión suficiente y ocurrió que al primer resquicio de fragilidad la unidad se rompió. La masonería española de Estados Unidos no escapó al problema; pareció recuperarse hacia 1918-1920 pero los masones yorkinos habían

${ }^{23}$ BOGOE nº 291, 31 julio 1916. 
aprovechado la situación para reclamar la absoluta soberanía sobre su territorio en detrimento del GOE. Y así comenzó su declive.

\section{La pérdida de los Estados Unidos}

La desaparición del GOE del territorio americano comenzó a gestarse casi en el mismo momento que llegó a Philadelphia aunque consiguió aguantar durante veintinueve años la batalla. Todo el problema se reducía a la jurisdicción masónica sobre el territorio americano, esto es: estados Unidos se regía por el sistema de Grandes Logias Regionales nacido de la Independencia y configurado como típicamente americano. Sobre ellos dos Supremos Consejos: unos con jurisdicción sobre el Norte con sede en Boston y otro para el Sur, con sede en Charlestown. Frente a esta masonería fuerte y organizada sólo hubo una mínima presencia peninsular que, además, prefirió aislarse tras los hechos ocurridos en el Congreso Masónico Internacional de Lausanne de 1875. En él, además de que España no estuvo presente, se acordó que tanto Cuba como Puerto Rico pasasen a ser administradas por Estados Unidos.

Aun así, el GOE accedió a auspiciar logias en territorio americano. Los americanos iniciaron una dura y persistente campaña contra el oriente español con el fin de echarlos y para ello se valieron de todo tipo de argucias, desde infiltraciones de masones americanos en las logias españolas hasta campañas de desprestigio en la prensa e incluso un juicio civil. Fue tan evidente esta soterrada declaración de guerra de la masonería del Rito de York que las logias españolas tuvieron que añadir en el juramento del grado de aprendiz un párrafo suficientemente revelador: "además prometo y juro no entrar en ninguna camarilla ni conspiración que pueda retardar el progreso del Gr... Or... Español en el continente de América" y para que no quedara duda aclaraban que habían hecho para proteger los talleres españoles de la influencia yorkina ${ }^{24}$.

En 1907, en la reunión internacional celebrada en Bruselas se estableció que: "Todo estado sobre el que no existiera Poder Supremo del Rito Escocés Antiguo y Aceptado, es un territorio en el cual cada Supremo Consejo puede establecer talleres de su obediencia, y donde ésos Supremos Consejos existan, en lo futuro, ningún cuerpo masónico del Rito será constituido por otra potencia que la local” ${ }^{, 25}$. Tras este decreto, la masonería española en suelo americano violaba el principio de territorialidad.

Las quejas norteamericanas se sucedieron y volvieron a la palestra en 1912, en el encuentro celebrado en Washington. Se acordó taxativamente que si España seguía auspiciando esas logias quedaría fuera del concierto de los Supremos Consejos, lo que la sumía en la irregularidad. España no estuvo presente en ninguna de las reuniones y no se le iba a dejar asistir a Lausanne mientras no acatara la condición impuesta.

Finalmente, y después de ser tema casi exclusivo en Lausanne, el GOE accedió a dejar sus logias norteamericanas conservando, eso sí, las que tenía en Puerto Rico y

\footnotetext{
${ }^{24}$ AHNS, Leg. 265-A.

${ }^{25}$ BOGOE, no 336,25 octubre 1922.
} 
Filipinas pues el hecho de que ambas fueran ahora de Estados Unidos se debía a una guerra, acto que estaba bastante lejos de las ideas pacifistas de la masonería.

La pérdida de la columna federal americana fue importante pues en ese momento contaba con treinta y siete logias. Sin embargo en España eran conscientes de que aquello talleres tenían una vida un tanto particular, estando unidos por flojos lazos que desviaban la atención de la propia España y eso no era beneficioso. En cuanto a las logias americanas, la mayoría pasaron a engrosar el registro de las Grandes Logias americanas.

\section{Conclusiones}

Es la escasez de información la que nos da la clave de lo que fueron las relaciones masónicas entre los dos países. La lejanía y el tiempo dificultaban los contactos y el acercamiento. Ello unido a la violación masónica territorial, le acarrearon una enemiga mucho más fuerte y poderosa, la masonería norteamericana.

El caso norteamericano cuenta con un número importante de masones en relación con España, ya que hemos censado más de tres mil, pero resulta insignificante si lo situamos en el contexto estadounidense. La masonería española que se afincó en aquel país fue una masonería de segundo orden, con una escasa implantación social; una masonería desideologizada, controlada por un grupo de clase media urbana que no se distinguió por su participación en el campo de la movilización social, la participación política o la afiliación sindical.

La vida de las logias, que a título particular hemos dejado fuera de este trabajo, se movió por los mismos derroteros. Sólo cuatro superaron la crisis del siglo XIX y si a alguien se debe ello fue al incansable trabajo de Harry Goode. Desaparecido él, la unión entre los talleres se resintió y nos encontramos ante unas logias con serios problemas de gobierno y organización interno, en las que los personalismos y los intereses particulares primaban por encima del pretendido bien común.

La Gran Logia acabó siendo un instrumento para conseguir prestigio ante la sociedad americana lo que propició el que, durante la segunda década del siglo XX, muchas de ellas prefirieran depender del Gran Consejo de la Orden.

En fin, lo que aparentemente parecía un asentamiento próspero y beneficioso, se tornó igual de desorganizado que lo que ya existía.

\section{Fuentes}

Archivo Histórico Nacional de Salamanca (AHNS), Leg. 265-A; Leg. 315-A.

Boletín Oficial del Gran Oriente Español (BOGOE).

Boletín de Procedimientos de la Gran Logia Simbólica Española (BP).

Brown, W. M. Freemasonry in Virginia (1733-1936). Richmond: Masonic Honne Press, 1936.

Claudy, Carl H. These were Brethren. Washington D. C.: Kingsport, 1947. 
Creigh, Alfred. Masonry and antimasonry. A histoty of Masonry, as it has existed in Pennsylvania since 1792. Philadelphia: Lippincott, Grambo \& Co., 1854.

Findel, J. G. The History of Freemasonry from its Origin Down to The Present Day. London: Asher \& C., 1927.

Hughan, W. J. "The two Carmik Ms" and the introduction of Freemasonry into Philadelphia, USA". Transactions of the Quatuor Coronati Lodge XXII (1909): 95-115.

\section{Bibliografía}

Allendesalazar, J. M. El 98 de los americanos, Cuadernos para el diálogo. Madrid: Edicusa, 1974.

Cerza, Alphonse. "La Masonería en Estados Unidos”. Historia 16 (1977): 87-94.

Degler, Carl N. Historia de Estados Unidos. El desarrollo de una nación (1860-1985). Barcelona: Ariel, 1986.

Ferrer Benimeli, José Antonio. Masonería, Iglesia e Ilustración. Madrid: Fundación Universitaria Española, 1977.

Ferrer Benimeli, José Antonio. La masonería española en el siglo XVIII. Madrid: Siglo XXI, 1986.

Ferrer Benimeli, José Antonio. Masonería española contemporánea. Madrid: Siglo XXI, 1980.

Frau, Lorenzo. Diccionario Enciclopédico de la Masonería. México D. F.: Ed. Valle de México, 1979.

Paz, Manuel de. Historia de la Francmasonería en Canarias (1739-1936). Santa Cruz de Tenerife: , Ediciones del Excmo. Cabildo Insular de Gran Canaria, 1984.

Seal-Coon, Frederic W. An Historical Account of Jamaican Freemasonry. Kingston: Golding Printing Service, 1976.

Tocqueville, Alexis de. La Democracia en América. Madrid: Alianza Ed., Madrid, 1961. 